\title{
The Welfare State as Safety Net in Migration Preferences: Empirical Evidence from an Experiment Among Dutch Master Students
}

\author{
Petra W. de Jong ${ }^{1}$ (D) $\cdot$ Kim Caarls $^{1} \cdot$ Helga A. G. de Valk ${ }^{1}$
}

Received: 9 September 2020 / Accepted: 16 July 2021 / Published online: 31 July 2021

(c) The Author(s) 2021

\begin{abstract}
The welfare state can be perceived as a safety net which helps individuals adjust to situations of risk or transition. Starting from this idea of the welfare state as safety net, this study addresses whether and how welfare generosity may influence people's willingness to migrate. In doing so, we distinguish between two potential mechanisms, innovatively focusing on welfare provisions in both the country of origin and destination. First, a generous welfare system in the country of origin may have a retaining impact, as individuals may be unwilling to migrate to countries offering less social protection. Second, generous welfare provisions in the country of destination may enable migration for individuals who are more intolerant of uncertainty and who otherwise would prefer to remain immobile. We test both mechanisms using stated preference data collected with a unique experimental design among over 300 Dutch Master students. Confirming the first mechanism, we indeed find that respondents report a lower willingness to migrate when evaluating hypothetical scenarios where the level of social protection was higher in the country of origin as compared with the country of destination. Furthermore, and in line with the second mechanism, individuals who are more intolerant of uncertainty generally report a lower willingness to migrate, yet their willingness to migrate increases for scenarios with higher levels of unemployment benefits. Our findings, thus, indeed suggest that welfare arrangements are mainly serving a safety net function and need to be understood in relative terms between the country of origin and destination.
\end{abstract}

Keywords Migration $\cdot$ Preferences $\cdot$ Welfare state $\cdot$ Experiment

Petra W. de Jong

p.w.dejong@essb.eur.nl

Helga A. G. de Valk

valk@nidi.nl

1 Netherlands Interdisciplinary Demographic Institute (NIDI)-KNAW/University of Groningen,

Lange Houtstraat 19, 2511CV The Hague, The Netherlands 


\section{Introduction}

Neoclassical models on international migration explain cross-border movements as the outcome of a rational cost-benefit analysis, and expect individuals to migrate when the returns of doing so exceed the costs (e.g., Stark, 1990). Yet while the neoclassical approach has dominated large parts of the literature on international migration, these models fail to explain why many people do not move, despite promising opportunities abroad. To address this limitation, over the past decade migration scholars have aimed at a better understanding of the process of migration decision-making (Carling \& Collins, 2018; De Haas, 2010; Koikkalainen \& Kyle, 2016). Many of these efforts have mentioned the high level of uncertainty associated with international migration decisions as one of the main reasons for flaws or oddities in individuals' subjective judgments when faced with 'logical choices' on whether or not to migrate (Czaika, 2015). Besides actual costs and benefits associated with migration, one could therefore expect macro- and micro-level factors related to (the perception of) uncertainty to play an important role in shaping migration preferences. To test this proposition, this study focuses on the influence of welfare arrangements on a person's willingness to migrate. After all, the welfare state protects individuals in case of unforeseen events, and as such may be important to mitigate uncertainty.

Based on the existing literature, we test two possible mechanisms through which welfare generosity may influence migration preferences. The first mechanism we study draws from the new economics of labor migration theory (or 'NELM') which has explained migration as a way of households or individuals to minimize risks, rather than to maximize income like predicted by neoclassical models (Massey, 1998; Stark \& Taylor, 1991). In line with this reasoning, migration scholars have argued that institutions in the country of origin have the capacity to mediate migration decisions, and that the willingness to migrate will be lower in origin countries where a generous welfare state protects against life uncertainties (Kureková, 2013; Massey, 1998). Unfortunately, however, empirical evidence on the role of the welfare state in the country of origin in migration decisions or preferences has been scarce, in part because the NELM functions as a micro-theory, and therefore does not directly address macro-institutional factors (Kureková, 2013). Moreover, because most migration studies focus on those individuals who actually migrated, the data typically used in migration research are ill-suited to investigate a possible retaining impact of generous welfare provisions in the country of origin.

The second mechanism we study builds on more recent literature that acknowledges the importance of personality traits to explain why some individuals are more open to migration than others. Several studies in this field reported that risk-seeking individuals are more likely to ever have migrated than individuals who are more risk-averse (Gibson \& McKenzie, 2011; Jaeger et al., 2010), and more often express migration aspirations (Van Dalen \& Henkens, 2008; Williams et al., 2018). Findings like these support the idea that migration decisions partly depend on psychological traits affecting the way in which people cope with 
risks or uncertainty. By protecting against risks, a generous welfare system in the country of destination may enable migration for individuals who otherwise would remain immobile. Yet so far, prior research has not been able to empirically test whether risk-averse individuals are indeed more willing to migrate in the presence of macro-level factors abroad that protect against risks, like the welfare state.

To test these expectations on the role of the welfare state as a safety net in migration decisions, this study introduces a stated preference approach. By means of specially designed questionnaires, stated preference studies aim to measure the importance of different attributes within a particular choice problem (see Louviere et al., 2000; Van De Vyvere, 1994). Thus, rather than capturing actual behavior (or 'revealed preferences'), the methodology builds on stated evaluations of hypothetical scenarios, collected in the setting of a controlled experiment. The methodology has been frequently applied in studies on (residential) mobility (e.g., Kim et al., 2005; Tillema et al., 2010; Walker et al., 2002), yet appears less common in the field of international migration. Here we apply the approach to investigate the importance of social protection levels (in this study captured by level and access to unemployment benefits and costs of healthcare) in the country of destination in comparison to the country of origin on individuals' willingness to migrate. To disentangle the role of the welfare state as a safety net from direct financial benefits associated with higher welfare provisions, we strategically test our hypotheses among a sample of over 300 Dutch Master students.

\section{Theory}

\section{Migration Preferences and the Welfare State as Safety Net}

Literature on international migration has frequently mentioned the welfare state as one of the factors influencing migration decisions (e.g., Beine et al., 2011; De Giorgi \& Pellizzari, 2009; Giulietti \& Wahba, 2012). Just like higher wages, migration scholars primarily expected generous welfare systems abroad to attract migrants, also known as the 'welfare magnet hypothesis' (e.g., Borjas, 1999). Some scholars further acknowledged that welfare arrangements in the country of destination may discourage migration when associated with higher costs (Geis et al., 2013), or when benefits are not directly accessible to migrants. Both mechanisms treat welfare arrangements as an alternative form of income, directly affecting the expected returns to migration. However, previous empirical studies have largely neglected the main function of the welfare state, namely to protect residents against life uncertainties (Heitmueller, 2005; Kureková, 2013).

Welfare systems mediate how individuals fare in domestic labor markets and help workers adjust to situations of risk or transition. Focusing on this function of the welfare state as a safety net, we can distinguish two additional ways in which welfare generosity may affect migration decisions. As a first mechanism, and in line with the NELM, migration scholars have expected migration aspirations to be lower in countries where the welfare state provides greater social security in the form of income 
support (De Haas et al., 2019; Kureková, 2013). This reasoning suggests a retaining impact of welfare generosity. In other words, individuals may value a generous welfare state in the country of origin as a safety net which they are unwilling to give up by migrating to countries offering less social protection (Fouarge \& Ester, 2008). Following this line of this reasoning, we can formulate the following expectation:

H1 Higher levels of social protection in the country of origin as compared with the country of destination will decrease the willingness to migrate.

As a second mechanism, psychological traits associated with the likelihood that people enter novel situations, as well as their affective reactions to it, have been used as predictors of an individual's aspiration to migrate (Boneva \& Frieze, 2001). Moving to a different country can give rise to strong feelings of uncertainty, as one has to adapt to an unfamiliar environment (Remhof et al., 2014; Tharenou, 2008). Indeed, previous studies have found that risk-averse individuals are generally less likely to migrate than those with greater tolerance of uncertainty (Gibson \& McKenzie, 2011; Jaeger et al., 2010; van Dalen \& Henkens, 2013). Yet because the welfare state protects residents against life uncertainties, individuals who are less tolerant of uncertainty may feel better protected against the risks associated with migration in the presence of a generous welfare state abroad. In line with this reasoning, Heitmueller (2005) has proposed a model where unemployment benefits particularly impact the migration decisions of risk-aversive individuals, as these benefits can act as an insurance devise. A study by Hoppe and Fujishiro (2015) further showed that persons with low generalized self-efficacy still managed to take concrete actions for migration when anticipated job benefits abroad were high. In a similar vein, we can derive the following expectations regarding the link between intolerance of uncertainty and welfare generosity:

H2 The willingness to migrate will be lower among individuals who are more intolerant of uncertainty; but:

H3 Higher levels of social protection in the country of destination will increase the willingness to migrate among individuals who are more intolerant of uncertainty.

\section{Limitations of Previous Work}

While the hypotheses listed above are not entirely new to the literature, testing them empirically still is, since doing so requires a different research design than is generally adopted in migration studies. As a first limitation of previous work, the migration literature is largely characterized by a 'mobility bias', since researchers typically examine migrants rather than non-migrants (see Carling, 2002; Czaika, 2015; Schewel, 2019). This bias is unfortunate, especially given the fact that the latter group makes up the majority within the population. By concentrating on existing migration flows, a retaining impact of favorable circumstances in the country of origin has been largely ignored. What is more, empirical research has mostly focused 
on migrant experiences after mobility and settlement. Due to this 'after-the-fact' nature of data collection, previous studies have hardly addressed early stages of the migration decision-making process (Kley, 2017; Koikkalainen \& Kyle, 2016). In turn, prior research provides limited insight into migration preferences, given the many constraints (e.g., budget, policies, social ties, culture) that typically prevent actual migration behavior from perfectly following such preferences.

As a final limitation, in testing the association between personality traits and migration decisions, previous studies mainly treated risk-aversion as independently affecting an individual's preparedness to migrate. Yet the level of uncertainty associated with the migration decision may vary with macro-level conditions in the country of origin and destination, such as the presence of generous welfare provisions abroad. While this suggests that personality traits and macro-level factors may interact in shaping migration decisions, to the best of our knowledge no previous study has been able to test this mechanism empirically due to a lack of suitable data.

\section{Advancing the Literature with an Experimental Design}

To address the limitations of previous work, this study introduces the experimental design of a stated preference approach. The method combines experimental elements with survey elements (for an overview, see Wallander, 2009). In the experimental part, respondents indicate for several hypothetical scenarios (or 'vignettes') to what extent they would be willing to migrate under the described circumstances. As a main advantage of this approach, the researcher may assume that only attributes which are explicitly included in the scenarios are taken into account by the respondents (see Van De Vyvere, 1994). In addition, the experimental setup of the survey allows to decompose the overall stated preferences into partial weights associated with each attribute of the scenarios. This way, a stated preference approach helps to gain insight into the influence of specific attributes on real-world choices. Here we apply the approach to study the influence of welfare generosity on the willingness to migrate.

As a further advancement, whereas previous studies testing the link between migration and personality have often operationalized personality traits by means of a single question (see Gibson \& McKenzie, 2011; Jaeger et al., 2010), this study uses a validated scale on intolerance of uncertainty. Including this scale in the questionnaire better allows us to test whether higher scores on intolerance of uncertainty are indeed associated with a lower preference for migration in general. Moreover, by combining respondents' scores on this scale with their evaluation of the vignettes, we are able to test whether the impact of the level of social protection on migration preferences varies with intolerance of uncertainty.

\section{A Focus on Dutch Master Students}

For the purpose of this study, we strategically focus on a sample of Dutch Master students, who are young and childless, and at the verge of entering the labor market. International moves over this life stage are typically part of exploring future social 
and professional opportunities (see Frändberg, 2014). Given their life stage and skill level, it seems unlikely that Master students will consider migration for the primary purpose of higher welfare benefits (e.g., Razin \& Wahba, 2015). Studying this group therefore helps to distinguish the importance of the welfare state as a safety net in migration preferences from a general attracting effect of higher welfare benefits abroad. Our focus on an origin context where welfare provisions are relatively high, the Netherlands, further allows us to gain insight into a possible retaining impact of generous welfare provisions in the country of origin. In our analyses we focus on those aspects of the welfare state that seem most relevant to our study population: the level and accessibility of unemployment benefits, as well as the costs of healthcare. Other welfare provisions, such as family benefits and old-age pensions, are deemed less relevant given the life stage of these respondents, and hence are not taken into consideration here.

\section{Data and Methods}

\section{Data Collection}

The data used in this study were collected within multiple Master programs at nine Dutch universities between November 2017 and March 2018. ${ }^{1}$ To recruit respondents, we asked course coordinators of diverse Master programs for permission to collect data among Master students within their course. To reach a substantial and diverse set of Master programs, we used contact information obtained from university websites, personal networks and snowballing techniques to approach a broad range of people. Once a course coordinator agreed to cooperate, we visited the affiliated university to personally introduce the study and distribute the questionnaires among Master students at the beginning or end of a lecture. Immediately after our introduction, the students independently filled out the questionnaire by means of a paper-and-pencil interview (PAPI). With few exceptions, all students present upon our visit participated in the study. While there are no signs of systematic non-response among the students, we should point out that social science students are overrepresented in our sample (84\%), due to higher response rates among the approached course coordinators in this field. To ensure that our findings do not depend on the university, Master program or study discipline (i.e., STEM versus the social sciences), we conducted additional analyses in which we controlled for these factors. Adding these controls to the models did not change the interpretation of our results.

\footnotetext{
${ }^{1}$ Erasmus University Rotterdam, Maastricht University, Radboud University, Technical University Delft, Tilburg University, University of Amsterdam (UvA), University of Groningen, Utrecht University, Vrije Universiteit Amsterdam (VU).
} 


\section{Measurement Instrument}

As mentioned above, the measurement instrument used for this study combines survey elements with experimental elements. The survey part of the questionnaire consisted of questions capturing respondents' background characteristics such as age, gender and partnership status, as well as the 12-item Intolerance of Uncertainty Scale as constructed and validated by Carleton et al. (2007). In the experimental part of the questionnaire, respondents were asked to rate six descriptions of hypothetical scenarios, or the so-called 'vignettes'. The vignettes were introduced as follows:

After graduation, your search for a job will start. You can choose to stay in the Netherlands or go abroad. Below you will find the descriptions of 6 countries. For each of these scenarios, please indicate to what extent you would be willing to migrate to this country as opposed to staying in the Netherlands.

For each hypothetical scenario, respondents rated their willingness to migrate twice: once for a stay of maximum 1 year, and once for a stay of more than 3 years. Information on the length of stay abroad was included for two reasons: on the one hand to ensure that respondents rated the scenarios while having comparable expectations regarding the time dimension, and on the other hand for the researchers to explore whether the importance of welfare generosity in migration preferences depends on the anticipated length of stay abroad. To avoid providing either too much or too little information, each vignette included a recommended number of six attributes (Auspurg \& Hinz, 2015). Besides characteristics of the welfare state we included job opportunities, wage levels and language difficulties. The attributes and their levels are listed in Table 1. The hypothetical scenarios described the characteristics of potential destination countries as compared with the origin country (i.e., "higher than," "comparable with," and "lower than"). Figure 1 presents an example of a vignette.

The levels of the six attributes were strategically varied across the vignettes to estimate the impact of each attribute on respondents' judgements. As each attribute had three levels, our vignette universe consisted of $3^{6}=729$ combinations. Given this high number, we could not present all combinations to our respondents. Instead, we obtained a D-efficient sample of 54 vignettes, using the modified Federov search algorithm in the so-called Resolution IV (D-efficiency $=93.97$; A-efficiency $=87.40 ;$ G-efficiency $=100.00)$. ${ }^{2}$ The D-efficiency score depends on the number of vignettes selected, the size of the vignette universe and the number of interactions between attributes. Although a higher D-efficiency score could be obtained by drawing a larger vignette sample, for practical reasons a vignette sample of 54 vignettes provided the most optimal solution between perfect orthogonality and balance (see Kuhfeld et al., 1994). Correlations across all

\footnotetext{
${ }^{2}$ In the search algorithm, we specified the following interaction terms to be tested: WageXUnemployment benefit level; WageXUnemployment benefit access; WageXCosts of healthcare; Job ChanceXUnemployment benefit level; Job ChanceXUnemployment benefit access; Unemployment benefit levelXUnemployment benefit access.
} 


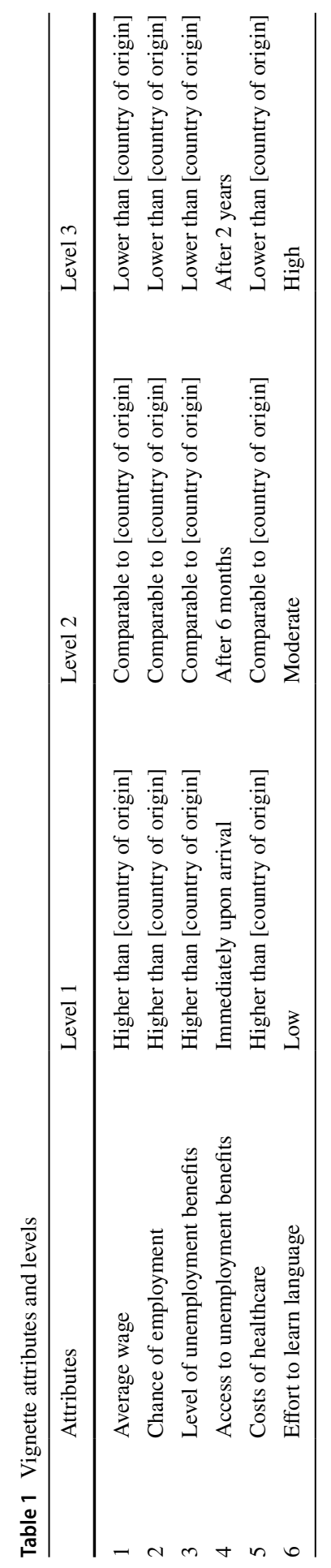


Imagine a country where the average wage after tax in jobs of your disciplinary scope is higher to the Netherlands.

Your chances to find an adequate job here are lower than in the Netherlands.

Unemployment benefits are lower than in the Netherlands.

Unemployment benefits are accessible 6 months after migration.

Personal costs of using healthcare of similar quality are higher than in the Netherlands.

For someone who speaks Dutch, it requires moderate effort to learn the language of this country.

To what extent would you be willing to move to this country for a maximum of one year?

$$
\begin{array}{llllllllllll}
\text { Not } & 1 & 2 & 3 & 4 & 5 & 6 & 7 & 8 & 9 & 10 & \text { Very } \\
\text { at all } & \square & \square & \square & \square & \square & \square & \square & \square & \square & \square & \text { Much }
\end{array}
$$

To what extent would you be willing to move to this country for more than three years?

$\begin{array}{llllllllllll}\text { Not } & 1 & 2 & 3 & 4 & 5 & 6 & 7 & 8 & 9 & 10 & \text { Very } \\ \text { at all } & \square & \square & \square & \square & \square & \square & \square & \square & \square & \square & \text { Much }\end{array}$

Fig. 1 Example of a vignette

attributes are displayed in Appendix Table 5. To avoid fatigue effects, we deemed it undesirable for respondents to evaluate more than six hypothetical destination country profiles (see Auspurg \& Hinz, 2015; Sauer et al., 2011). In turn, the vignettes were randomly distributed to nine questionnaire versions, each containing six vignettes.

In designing the questionnaire, we carefully considered the order of the different survey elements. Placing the Intolerance of Uncertainty Scale after the experimental part may lead to a post-treatment bias in the final model in case the moderator (intolerance of uncertainty) is affected by the experiment (Montgomery et al., 2018). Yet although it is possible that thinking about migration influences respondents' assessment of their own tolerance of uncertainty, the literature on personality traits generally perceives these traits to be relatively stable within a person, and hence more or less consistent under different circumstances (e.g., Boneva \& Frieze, 2001; Carleton et al., 2007). On the other hand, measuring respondents' intolerance of uncertainty on the 12-item scale before assessing their migration preferences could prime respondents in such way that they are more aware of the uncertainty in migration when evaluating the vignettes. Such priming effects may compromise the results of the entire study (Montgomery 
et al., 2018). After weighing both options, we therefore decided to capture intolerance of uncertainty at the end of the survey, after the experimental part. It should be noted that because of this design, post-treatment effects cannot be ruled out completely in the final model.

\section{Variables}

\section{Stated Preferences and Scenario Attributes}

For each scenario, respondents were asked: (a) "To what extent would you be willing to move to this country for a maximum of 1 year?" and (b) "To what extent would you be willing to move to this country for more than 3 years?". The answer scale ranged from $1=$ not at all to $10=$ very much. In the analyses we treat these Likert scales as continuous dependent variables, capturing respondents' stated preferences for short-term and long-term moves. The vignette attributes 'wage', 'job chances', 'level of unemployment benefits', 'access to unemployment benefits', 'costs of healthcare' and 'effort to learn the language' enter the analyses as categorical independent variables.

\section{Intolerance of Uncertainty}

To test our expectations regarding a person's innate ability to deal with uncertainty, we used respondents' scores on the Intolerance of Uncertainty scale (Carleton et al., 2007). The scale consists of 12 statements about uncertainty, for which respondents were asked to indicate to what extent each statement is characteristic of them on a scale from 1 ("Not at all characteristic of me") to 5 ("Entirely characteristic of me"). ${ }^{3}$ First, we conducted a factor analysis to confirm that the 12 items of the Intolerance of Uncertainty Scale loaded on a single factor, which was indeed the case (Cronbach's alpha $=.87$ ). Next, we calculated each respondent's average score based on the 12 items of the scale. This resulted in values between 1.08 and 4.67, with higher scores indicating a higher intolerance of uncertainty.

\section{Demographic Characteristics}

Our focus on Master students resulted in a homogeneous sample in terms of life stage and skill level. However, from previous research we know that migration preferences may also vary with other demographic characteristics. First, prior studies have shown that having a partner generally decreases the preparedness to migrate across borders (Dustmann et al., 1996). The strongest impact is expected for individuals who live together with their partner, as international migration in this case likely becomes a household decision. Second, individuals who migrated in the past probably gained experience living across borders, which may result in a higher

\footnotetext{
${ }^{3}$ Examples of statements are "It frustrates me not having all the information I need"; "One should always look ahead so as to avoid surprises"; "I should be able to organize everything in advance".
} 
willingness to migrate again (e.g., Deléchat, 2001; Van Mol, 2016). Besides the six vignette attributes, intolerance of uncertainty scores and standard control variables for sex and age, we therefore include partnership status and migration experience. The variable 'partnership status' distinguishes persons who are single, persons who have a partner but do not cohabite and persons who are cohabiting with their partner. The variable 'migration experience' captures whether a respondent ever lived outside the origin country for more than three months $(1=$ at least once, $0=$ never $)$. Finally, the presented models include vignette order and questionnaire version to control for possible effects of the design of the questionnaire. ${ }^{4}$

\section{Sample}

The total sample consisted of 467 respondents, together evaluating a total of 2802 vignettes. Because comparing a hypothetical destination country to the Netherlands in the vignettes likely has a different meaning for foreign-born students, we only included individuals born in the Netherlands $(n=319)$. Having children likely has an impact on one's migration preferences, yet within our sample the share of respondents who indicated to have children was too small to analyze. We therefore excluded respondents with children from our sample $(n=3)$. We further excluded respondents with missing values on more than one item of the intolerance of uncertainty scale $(n=5)$, as well as those who did not indicate their sex $(n=2)$, resulting in an anlytical sample of 309 respondents. After removing vignettes without an evaluation $(n=2)$ we obtained our final sample of 1852 vignettes.

Table 2 presents the descriptive statistics of the sample. Respondents were between 21 and 34 years old, with the majority being around 24 years old. In line with the gender distribution of students in the social sciences, males formed a minority in our sample: 35 per cent versus 65 per cent of females. ${ }^{5}$ Within the sample, around 43 per cent of the respondents were single, 40 per cent had a partner but did not cohabite, and 17 per cent lived together with their partner. A substantial share of the sample, nearly 39 per cent, ever lived outside the Netherlands for at least three months. Individuals in our sample on average scored moderate on intolerance of uncertainty ( 2.38 on a scale from one to five, with higher scores representing higher intolerance of uncertainty).

\section{Analytical Strategy}

As each person evaluated six different vignettes, the models had to be corrected for correlated observations, as is the case with any repeated measures in within-subject designs (Hox et al., 1991). We therefore applied random intercept models that account for dependent observations by estimating one joint random intercept for all

\footnotetext{
${ }^{4}$ For reasons of readability, coefficients of the control variables regarding the design of the questionnaire are not presented in the tables below but are available upon request.

5 In 2015, of the Master students who graduated from a Dutch university in the field of social science $26.33 \%$ were males, versus $73.67 \%$ females (Van Mol et al., 2018).
} 
Table 2 Sample description

\begin{tabular}{lcccc}
\hline Variable & Mean/\% & SD & Range & Median \\
\hline Stated preference to migrate & & & & \\
Maximum 1 year & 5.30 & 2.42 & $1-10$ & 6 \\
More than 3 years & 4.07 & 2.34 & $1-10$ & 4 \\
Questionnaire & & & $1-9$ & \\
Version 1 & 11.66 & & & \\
Version 2 & 10.69 & & & \\
Version 3 & 9.72 & & & \\
Version 4 & 11.99 & & & \\
Version 5 & 10.31 & & & \\
Version 6 & 11.61 & & & \\
Version 7 & 11.66 & & & \\
Version 8 & 10.37 & & & \\
Version 9 & 11.99 & & & \\
Sex & & & & \\
Male & 35.31 & & & \\
Female & 64.69 & & & \\
Age & 23.84 & 1.97 & & \\
Partnership status & & & & \\
No partner & 42.71 & & & \\
Partner, not cohabiting & 40.17 & & & \\
Cohabiting long-term & 17.12 & & & \\
Migration experience & & & & \\
Yes & 38.88 & & & \\
No & & & & \\
N & & & & \\
\hline
\end{tabular}

observations from one single respondent (Bryk \& Raudenbush, 1992; Snijders \& Bosker, 2012). Characteristics of the vignettes vary on Level 1; individual characteristics are modeled as Level 2 variables.

\section{Results}

\section{Migration Preferences}

Figure 2 displays the distribution of respondents' stated preference to migrate for a maximum of 1 year and more than 3 years under the hypothetical scenarios. As shown by the median, respondents rated their willingness to migrate short-term (maximum 1 year) with a 6 out of 10 or higher for the majority of the vignettes. The willingness to migrate long-term (more than 3 years) was clearly much lower, as indicated by the median at 4 out of 10 . Compared with previous surveys among 

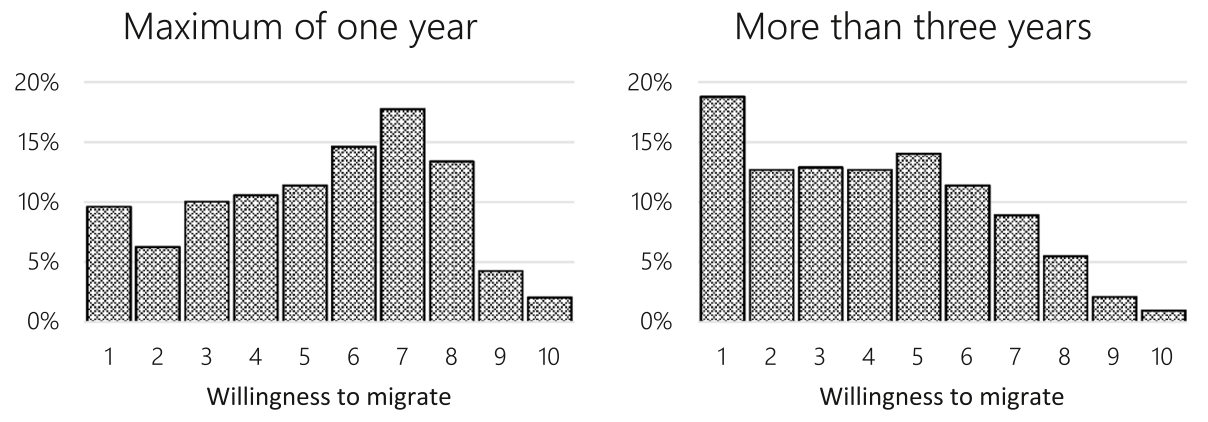

Fig. 2 Distribution of the dependent variable: stated preference to migrate for a maximum of 1 year and more than 3 years

couples (Abraham et al., 2010) and academic staff (Petzold, 2017), these figures indicate that Master students generally display a relatively high willingness to migrate, even for long-term moves. This is in line with prior research illustrating that students tend to express higher mobility intentions as compared to those not enrolled in education (Van Mol, 2016). The ratings of the vignettes are not normally distributed, especially for long-term moves (see Fig. 2). However, because ordered logistic regression models yielded substantially similar results, we continue below with the more straightforward interpretation of a linear regression model.

\section{Null Model and Main Effects of Vignette Characteristics}

We start by estimating an empty model (Model 0 , Tables 3 and 4). The intraclass correlation (ICC) indicates that for short-term moves about 53 per cent of the variance in stated preferences can be attributed to the individual level, and for longer moves as much as 60 per cent of the variance. Thus, differences between individuals clearly explain a large part of the variation in the willingness to migrate. We pursue with a random intercept model only containing the vignette characteristics (Model 1, Tables 3 and 4). Here the effects of the vignette variables represent a shared understanding of how the vignettes' attributes affected respondents' judgments. For both short-term and longer moves, the main effects of the vignette characteristics are broadly in line with general 'push-pull' models. That is, the willingness to migrate is higher when wages and job prospects in the described country of destination are better than in the country of origin, and lower when they are worse, or when it requires greater effort to learn the language of the country of destination. Yet when we turn to our main variables of interest, we notice an interesting pattern regarding the impact of welfare generosity on migration preferences.

First, and still in line with neoclassical models, the findings show that respondents' willingness to migrate is higher for scenarios where the level of unemployment benefits is higher in the country of destination as compared to the country of origin. However, lower levels of unemployment benefits in the country of destination have a stronger negative impact on the willingness to migrate than higher levels abroad have a positive effect, as indicated by the effect sizes. Overall, respondents seem more concerned 
Table 3 Summary of linear regression analysis for variables predicting the stated preference to migrate for a maximum of 1 year (random intercept models)

\begin{tabular}{|c|c|c|c|c|c|c|c|c|}
\hline & \multicolumn{2}{|l|}{ Model 0} & \multicolumn{2}{|l|}{ Model 1} & \multicolumn{2}{|l|}{ Model 2} & \multicolumn{2}{|l|}{ Model 3} \\
\hline & $\mathrm{B}$ & $(\mathrm{SE})$ & $\mathrm{B}$ & (SE) & $\mathrm{B}$ & $(\mathrm{SE})$ & $\mathrm{B}$ & $(\mathrm{SE})$ \\
\hline \multicolumn{9}{|l|}{ Wage (ref comparable) } \\
\hline Higher & & & $.42 * * *$ & $(0.08)$ & $0.42 * * *$ & $(0.08)$ & $0.42 * * *$ & $(0.08)$ \\
\hline Lower & & & $-.49 * * *$ & $(0.08)$ & $-0.49 * * *$ & $(0.08)$ & $-0.49^{* * *}$ & $(0.08)$ \\
\hline \multicolumn{9}{|l|}{$\begin{array}{l}\text { Job chances (ref com- } \\
\text { parable) }\end{array}$} \\
\hline Higher & & & $.51 * * *$ & $(0.09)$ & $0.51 * * *$ & $(0.09)$ & $0.51 * * *$ & $(0.09)$ \\
\hline Lower & & & $-.87 * * *$ & $(0.09)$ & $-0.88 * * *$ & $(0.09)$ & $-0.87 * * *$ & $(0.09)$ \\
\hline \multicolumn{9}{|l|}{$\begin{array}{l}\text { Level of Unemp. Ben. } \\
\text { (ref comparable) }\end{array}$} \\
\hline Higher & & & $.20^{*}$ & $(0.08)$ & $0.20^{*}$ & $(0.08)$ & -0.34 & $(0.26)$ \\
\hline Lower & & & $-.32 * * *$ & $(0.08)$ & $-0.32 * * *$ & $(0.08)$ & $-0.32 * * *$ & $(0.08)$ \\
\hline \multicolumn{9}{|l|}{$\begin{array}{l}\text { Access to Unemp. Ben. } \\
\text { (ref } 6 \text { months) }\end{array}$} \\
\hline Immediately & & & $.25 * *$ & $(0.08)$ & $0.25^{* *}$ & $(0.08)$ & $0.25 * *$ & $(0.08)$ \\
\hline 2 years & & & $-.19 *$ & $(0.08)$ & $-0.19 *$ & $(0.08)$ & $-0.19 *$ & $(0.08)$ \\
\hline \multicolumn{9}{|l|}{$\begin{array}{l}\text { Costs of healthcare (ref } \\
\text { comparable) }\end{array}$} \\
\hline Higher & & & $-.41 * * *$ & $(0.08)$ & $-0.41 * * *$ & $(0.08)$ & $-0.40 * * *$ & $(0.08)$ \\
\hline Lower & & & -.04 & $(0.08)$ & -0.04 & $(0.08)$ & -0.04 & $(0.08)$ \\
\hline \multicolumn{9}{|l|}{$\begin{array}{l}\text { Effort to learn language } \\
\text { (ref moderate) }\end{array}$} \\
\hline High & & & $-.64 * * *$ & $(0.08)$ & $-0.64 * * *$ & $(0.08)$ & $-0.64 * * *$ & $(0.08)$ \\
\hline Low & & & $.27 * * *$ & $(0.08)$ & $0.27 * * *$ & $(0.08)$ & $0.27 * * *$ & $(0.08)$ \\
\hline Male & & & & & 0.31 & $(0.22)$ & 0.31 & $(0.22)$ \\
\hline Age & & & & & 0.04 & $(0.05)$ & 0.04 & $(0.05)$ \\
\hline \multicolumn{9}{|l|}{$\begin{array}{l}\text { Partnership status (ref } \\
\text { single) }\end{array}$} \\
\hline Partner, not cohabiting & & & & & -0.16 & $(0.22)$ & -0.16 & $(0.22)$ \\
\hline Partner, cohabiting & & & & & $-0.59 *$ & $(0.29)$ & $-0.59 *$ & $(0.29)$ \\
\hline Migration experience & & & & & $0.90 * * *$ & $(0.21)$ & $0.91 * * *$ & $(0.21)$ \\
\hline $\begin{array}{l}\text { Intolerance of uncer- } \\
\text { tainty }\end{array}$ & & & & & $-0.34 *$ & $(0.16)$ & $-0.41 *$ & $(0.16)$ \\
\hline $\begin{array}{l}\text { Intol. Uncert.*Unemp. } \\
\text { Ben. higher }\end{array}$ & & & & & & & $0.23 *$ & $(0.11)$ \\
\hline Constant & $5.30 * * *$ & $(0.11)$ & $6.28 * * *$ & $(0.33)$ & $5.74 * * *$ & $(1.32)$ & $5.92 * * *$ & $(1.33)$ \\
\hline Variance (respondents) & $3.06 * * *$ & $(0.28)$ & $3.01 * * *$ & $(0.27)$ & $2.67 * * *$ & $(0.24)$ & $2.67 * * *$ & $(0.24)$ \\
\hline Variance (vignettes) & $2.72 * * *$ & $(0.10)$ & $1.84 * * *$ & $(0.07)$ & $1.84 * * *$ & $(0.07)$ & $1.84 * * *$ & $(0.07)$ \\
\hline $\mathrm{N}$ vignettes & 1852 & & 1852 & & 1852 & & 1852 & \\
\hline $\mathrm{N}$ respondents & 309 & & 309 & & 309 & & 309 & \\
\hline Log likelihood & -3869.55 & & -3560.7 & & -3543.91 & & -3541.61 & \\
\hline
\end{tabular}

Standard errors in parentheses, $* p<0.05, * * p<0.01, * * * p<0.001$ 


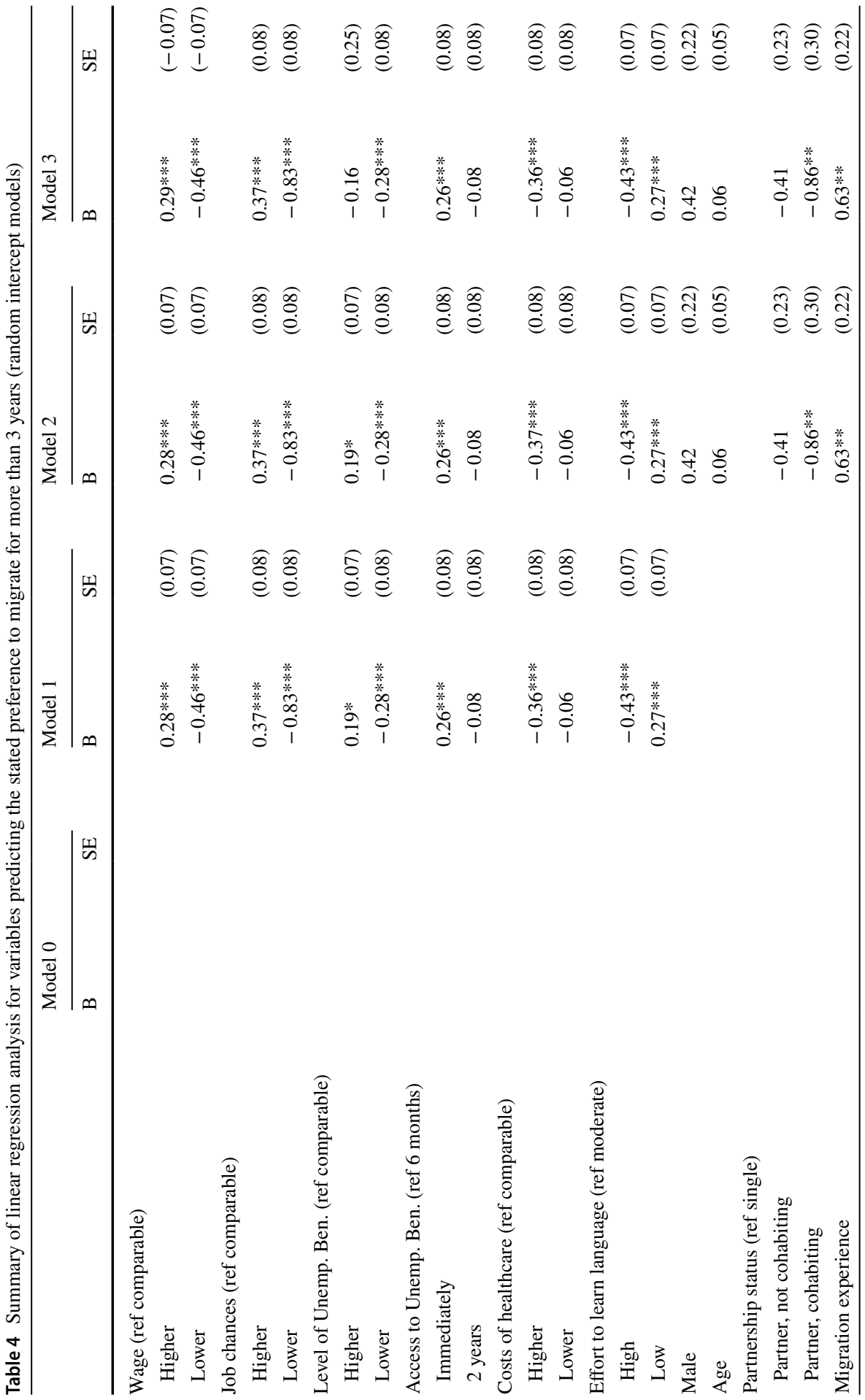




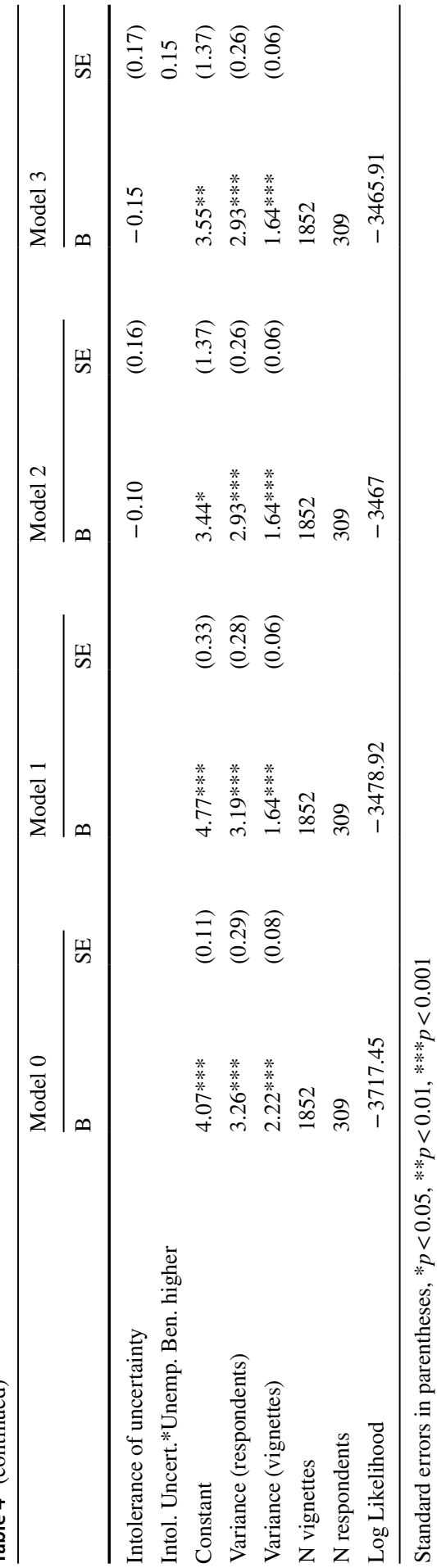


about losing what they already have through migration than they are about securing an equivalent gain. Yet as Master students are unlikely to receive unemployment benefits at the moment of data collection, this finding cannot be explained as a rational fear of respondents to lose actual income in the form of these benefits. Rather, respondents seem to evaluate the level of social protection that is available in case of unforeseen events in the future, supporting our notion of the welfare state as a safety net. In a similar vein, respondents' willingness to migrate is lower when personal costs of healthcare are higher in the country of destination as compared to the country of origin, while lower costs of healthcare abroad do not have a significant impact on the willingness to migrate. Again, these findings contradict a simple 'cost-benefit' calculation, as this would also entail a preference for migration in case of lower healthcare costs abroad. Instead, the findings indicate that respondents are especially reluctant to lose the level of support they currently have in their country of origin. Both findings support $\mathrm{H} 1$ that higher levels of social protection in the country of origin as compared with the country of destination decrease the willingness to migrate. Finally, we observe that a waiting time of 2 years to access unemployment benefits in the country of destination reduces the willingness to migrate, yet only for moves of less than a year. Apparently, it is not the waiting time of 2 years per se that reduces individuals' migration preferences, but rather the prospect of going unprotected by the welfare state over the full length of one's expected stay. This finding again highlights the role of the welfare state as a safety net in migration decisions.

\section{Effects of Personality and Demographic Characteristics}

In the next step we added respondents' personal characteristics to the model (Model 2, Tables 3 and 4). In line with $\mathrm{H} 2$, the willingness to migrate was generally lower among individuals who are more intolerant of uncertainty, yet only for moves of less than a year. No significant effect of intolerance of uncertainty was found on the willingness to migrate for more than 3 years. As a possible explanation, individuals who are less tolerant of uncertainty may prefer to make long-term plans in order to perceive control over their life, and hence may especially perceive short-term stays abroad as less attractive. Unfortunately, the literature provides limited leads on such interaction between personality and the length of migration. Additional research is therefore needed to investigate this unexpected finding in greater detail. Regarding the demographic characteristics, we further could observe significant effects for partnership status and previous migration experience. The willingness to migrate was rated lower among individuals who cohabite with their partner, especially for long-term moves. Individuals who ever lived outside the Netherlands for at least three months on the other hand generally expressed a higher willingness to migrate, with the strongest impact for short-term moves.

\section{Interactions with Intolerance of Uncertainty}

As our final step, we include a cross-level interaction between higher levels of unemployment benefits in the country of destination and intolerance of uncertainty to test our third hypothesis (Model 3, Tables 3 and 4). In line with H3, the willingness to 
migrate short-term was higher among individuals who are more intolerant of uncertainty when the level social protection in the country of destination is higher, possibly by providing a sense of protection against the risks associated with migration. This way, welfare arrangements may encourage people to migrate who otherwise would remain immobile. However, because we did not find a significant impact of intolerance of uncertainty for the willingness to migrate for more than 3 years to begin with, we do not observe a similar effect for long-term moves.

\section{Discussion}

With this study, we aimed to advance our knowledge on the influence of welfare generosity (captured by level and accessibility of unemployment benefits, and costs of healthcare) on migration preferences. In doing so we focused on a main, yet often neglected function of the welfare state, namely to protect residents against life uncertainties (Heitmueller, 2005; Kureková, 2013). To disentangle the role of the welfare state as a safety net from a potential attracting effect of higher welfare benefits abroad, we strategically focused on a sample of Dutch Master students, who are unlikely to consider migration for the primary purpose of higher welfare benefits (see Cohen \& Razin, 2008; Razin \& Wahba, 2015). Moreover, to overcome the data limitations of previous research, we introduced the experimental design of a stated preference approach. This way, we were able to empirically test two underexplored mechanisms through which welfare generosity may influence migration preferences.

First, we expected higher levels of social protection in the country of origin as compared with the country of destination to decrease the willingness to migrate (H1). In line with this expectation, we found that respondents stated a lower willingness to migrate when (i) the level of unemployment benefits was lower in the country of destination than in the origin country; (ii) the personal costs of healthcare were higher in the country of destination than in the origin country; (iii) waiting times to access unemployment benefits in the country of destination exceeded the full length of the expected stay abroad. These findings support our hypothesis that individuals are less willing to migrate to countries that offer less social protection than the country of origin, and stress the role of the welfare state as a safety net in international migration decisions.

Second, we expected individuals who are more intolerant of uncertainty to generally express a lower willingness to migrate $(\mathrm{H} 2)$, yet anticipated their willingness to migrate to be higher for destination countries with more generous welfare provisions (H3). A well-established scale on intolerance of uncertainty enabled us to test these expectations. In line with $\mathrm{H} 2$, the willingness to migrate short-term was generally lower among individuals who scored higher on intolerance of uncertainty. This finding supports the claim of previous research that personality traits provide an explanation why some individuals choose to migrate, whereas others under similar circumstances choose to stay (Boneva \& Frieze, 2001). However, and new to the literature, individuals who are more intolerant of uncertainty in our study reported a higher willingness to migrate short-term when unemployment benefit levels in the destination country were higher. These 
findings possibly indicate that macro-level factors like the welfare state lower the level of risk or uncertainty associated with migration decisions, this way enabling migration for individuals who generally feel less comfortable entering novel and uncertain situations.

The findings of this study provide empirical support for the idea that a generous welfare state in the country of origin can have a retaining impact on the willingness to migrate, even in life stages and socio-economic positions where individuals are least reliant on welfare provisions as we found these results among a sample of Master students. This retaining impact of welfare generosity may be particularly strong for countries of origin with a generous welfare state, like the Netherlands. Thus, we can conclude that it is essential to include the country of origin in studies on how welfare systems may operate and potentially influence migration preferences. At the same time, from our study it still remains unanswered whether welfare systems will have the same importance in all countries of origin, and among all populations.

Despite important advantages of our approach, some limitations should be kept in mind as well. First, experiments are designed to be relatively simple in order to enhance control and examine targeted aspects of the subject under study (Friedman \& Sunder, 1994). In our design, we describe hypothetical destination countries by six attributes, which is clearly a reduction of the more complex reality. While one could easily think of other interesting factors to play a role in migration choices, the number of attributes included in the vignettes has to be limited to prevent overwhelm among respondents. As second drawback, and while highly skilled individuals are generally better able to realize their migration intentions, from our study it remains unclear to what extent the reported migration preferences are indicative of actual migration behavior. The best way to test for such external validity would be the so-called 'before/after' study, where stated preferences are compared to subsequent choice behavior. Unfortunately, applying this kind of study is very complex in the context of international migration. As we cannot sufficiently address this issue here, we consciously stay away from predicting actual migration movements based on our findings. Third, our sample consists of Dutch Master students: a homogeneous, yet clearly selective target group. While our focus on this group has important advantages for the purpose of this study, it remains unclear to what extent our findings are generalizable to other populations, or alternative locations. Specifically, whereas we focus on the migration preferences of young and high-skilled individuals, the literature has suggested that welfare arrangements are particularly important to individuals with lower skill levels (Razin \& Wahba, 2015), or at life stages associated with specific welfare provisions (De Jong \& De Valk, 2019). This could mean that our findings will be simply more pronounced for populations with different welfare needs (e.g., parents, elderly, low educated). However, based on our sample we cannot be certain of the transferability of our findings. To be able do so, the experiment has to be replicated in future research among different target groups. Finally, intolerance of certainty scores may be associated with other unobserved characteristics, like socio-economic status. Because our sample of Master students is fairly homogeneous in terms of life stage and socio-economic position, the impact of such unobserved heterogeneity on the results of the final model can be expected to be relatively modest, although we cannot rule it out completely. Future research should 
be aware of the impact of such potential confounding factors, especially when replicating this study for different, more heterogeneous subpopulations.

While generous welfare provisions are often conceptualized as 'welfare magnets' in relation to international migration, our study emphasizes the need to focus more on the role of the welfare state as a form of protection. This recommendation also applies to the political domain, where the 'welfare magnet hypothesis' has been frequently used to motivate measures that limit immigrants' welfare access, especially in the context of free mobility within the European Union (EU) (Lafleur \& Mescoli, 2018; Ruhs, 2015). While such measures mainly aim to reduce the number of lowskilled immigrants, our findings suggest that restricting welfare access may also affect the migration preferences of the highly skilled. What is more, as individuals appear less willing to migrate in the absence of the safety net the welfare system provides, measures that restrict EU migrants' welfare access may hinder freedom of movement, one of the fundamental principles of the EU. Thus, and while our study has captured stated rather than observed preferences, our findings suggest that restricting immigrants' welfare rights may have unintended side effects on the preparedness to move among the highly educated.

Finally, while this study has looked at a specific relation, namely the role of the welfare state as safety net in the willingness to migrate, insights from the study can contribute to the broader migration literature in at least two more general ways. On the one hand, our findings demonstrate the importance of understanding preferences regarding whether or not to migrate not just from opportunities in the country of destination, but also from potential losses in the country of origin. This insight helps to explain why many people do not move, despite promising opportunities abroad (see Czaika, 2015; Schewel, 2019) and serves as an important call to overcome the dominant "destination country bias" among researchers and policymakers. On the other hand, and while previous studies have mainly looked at personality traits to explain why some people are more prone to migrate then others, our study provides initial support that personality traits may also affect which factors are considered most relevant by an individual in the process of migration decision-making. The findings confirm that different persons may value the same macro-level factors in different ways when deciding about migration, depending on their personality traits. In other words, personality traits may not only affect people's general openness to the option of migration, but also the type of pre-conditions that need to be fulfilled to prefer moving abroad over staying in the country of origin. Both insights help explain why migration flows do not necessarily follow neoclassical predictions, and require - at least conceptually — a shift away from 'one-size-fits-all' types of migration models.

\section{Appendix}

See Table 5 . 
Table 5 Correlations between vignette attributes (estimation sample)

\begin{tabular}{|c|c|c|c|c|c|c|}
\hline & 1 & 2 & 3 & 4 & 5 & 6 \\
\hline 1. Wage & - & & & & & \\
\hline 2. Job & -0.006 & - & & & & \\
\hline 3. Unemployment benefit level & -0.005 & 0.005 & - & & & \\
\hline 4. Unemployment benefit access & 0.006 & 0.030 & -0.002 & - & & \\
\hline 5. Costs of healthcare & 0.001 & 0.011 & 0.015 & -0.006 & - & \\
\hline 5. Effort to learn language & -0.009 & 0.005 & 0.006 & 0.006 & -0.001 & - \\
\hline
\end{tabular}

Acknowledgements This work is part of the MobileWelfare project supported by NORFACE Grant 46214-150. The authors thank the anonymous reviewers for their critical evaluation of an earlier version of this paper and their constructive criticism.

Data Availability The data that support the findings of this study were collected within the MobileWelfare project and are available on request from the MobileWelfare project leader (de Valk) and corresponding author (de Jong). The data are currently processed to be deposited at the Dutch data repository DANS.

\section{Declarations}

Conflict of interest No potential conflict of interest was reported by the authors.

Open Access This article is licensed under a Creative Commons Attribution 4.0 International License, which permits use, sharing, adaptation, distribution and reproduction in any medium or format, as long as you give appropriate credit to the original author(s) and the source, provide a link to the Creative Commons licence, and indicate if changes were made. The images or other third party material in this article are included in the article's Creative Commons licence, unless indicated otherwise in a credit line to the material. If material is not included in the article's Creative Commons licence and your intended use is not permitted by statutory regulation or exceeds the permitted use, you will need to obtain permission directly from the copyright holder. To view a copy of this licence, visit http://creativecommons.org/licen ses/by/4.0/.

\section{References}

Abraham, M., Auspurg, K., \& Hinz, T. (2010). Migration decisions within dual-earner partnerships: A test of bargaining theory. Journal of Marriage and Family, 72(4), 876-892.

Auspurg, K., \& Hinz, T. (2015). Factorial survey experiments. Sage Publications.

Beine, M., Docquier, F., \& Ozden, C. (2011). Diasporas. Journal of Development Economics, 95(1), 30-41. https://doi.org/10.1016/j.jdeveco.2009.11.004

Boneva, B. S., \& Frieze, I. H. (2001). Toward a concept of a migrant personality. Journal of Social Issues, 57(3), 477-491. https://doi.org/10.1111/0022-4537.00224

Borjas, G. J. (1999). Immigration and welfare magnets. Journal of Labor Economics, 17(4), 607-637. https://doi.org/10.1086/209933

Bryk, A. S., \& Raudenbush, S. W. (1992). Hierarchical linear models: Applications and data analysis methods. Sage.

Carleton, R. N., Norton, P. J., \& Asmundson, G. J. G. (2007). Fearing the unknown: A short version of the Intolerance of Uncertainty Scale. Journal of Anxiety Disorders, 21(1), 105-117. https:// doi.org/10.1016/j.janxdis.2006.03.014 
Carling, J. (2002). Migration in the age of involuntary immobility: Theoretical reflections and Cape Verdean experiences. Journal of Ethnic and Migration Studies, 28(1), 5-42. https://doi.org/10. $1080 / 13691830120103912$

Carling, J., \& Collins, F. (2018). Aspiration, desire and drivers of migration. Journal of Ethnic and Migration Studies, 44(6), 909-926.

Cohen, A., \& Razin, A. (2008). The skill composition of immigrants and the generosity of the welfare state: Free vs. policy-controlled migration Discussion Paper Series. Centre for Economic Policy Research.

Czaika, M. (2015). Migration and economic prospects. Journal of Ethnic and Migration Studies, 41(1), 58-82. https://doi.org/10.1080/1369183X.2014.924848

De Giorgi, G., \& Pellizzari, M. (2009). Welfare migration in Europe. Labour Economics, 16(4), 353363. https://doi.org/10.1016/j.labeco.2009.01.005

De Haas, H. (2010). Migration and development: A theoretical perspective. International Migration Review, 44(1), 227-264. https://doi.org/10.1111/j.1747-7379.2009.00804.x

De Haas, H., Czaika, M., Flahaux, M. L., Mahendra, E., Natter, K., Vezzoli, S., \& Villares-Varela, M. (2019). International migration: Trends, determinants, and policy effects. Population and Development Review, 45(4), 885-922.

De Jong, P. W., \& De Valk, H. A. G. (2019). Intra-European migration decisions and welfare systems: The missing life course link. Journal of Ethnic and Migration Studies. https://doi.org/10.1080/ 1369183X.2019.1611421

Deléchat, C. (2001). International migration dynamics: The role of experience and social networks. Labour, 15(3), 457-486. https://doi.org/10.1111/1467-9914.00173

Dustmann, C., Bentolila, S., \& Faini, R. (1996). Return migration: The European experience. Economic Policy, 11(22), 213-250.

Fouarge, D., \& Ester, P. (2008). How willing are Europeans to migrate? A comparison of migration intentions in Western and Eastern Europe. In P. Ester, R. Muffels, J. Schippers, \& T. Wilthagen (Eds.), Innovating European labour markets: Dynamics and perspectives (pp. 49-72). Edward Elgar.

Frändberg, L. (2014). Temporary transnational youth migration and its mobility links. Mobilities, 9(1), 146-164. https://doi.org/10.1080/17450101.2013.769719

Friedman, D., \& Sunder, S. (1994). Experimental methods: A primer for economists. Cambridge University Press. https://doi.org/10.1017/CBO9781139174176

Geis, W., Uebelmesser, S., \& Werding, M. (2013). How do migrants choose their destination country? An analysis of institutional determinants. Review of International Economics, 21(5), 825-840.

Gibson, J., \& McKenzie, D. (2011). The microeconomic determinants of emigration and return migration of the best and brightest: Evidence from the Pacific. Journal of Development Economics, 95(1), 18-29. https://doi.org/10.1016/j.jdeveco.2009.11.002

Giulietti, C., \& Wahba, J. (2012). Welfare migration. IZA DP, Institute for the Study of Labor, 6450.

Heitmueller, A. (2005). Unemployment benefits, risk aversion, and migration incentives. Journal of Population Economics, 18(1), 93-112.

Hoppe, A., \& Fujishiro, K. (2015). Anticipated job benefits, career aspiration, and generalized self-efficacy as predictors for migration decision-making. International Journal of Intercultural Relations, 47, 13-27. https://doi.org/10.1016/j.ijintrel.2015.03.025

Hox, J. J., Kreft, I. G. G., \& Hermkens, P. L. J. (1991). The analysis of factorial surveys. Sociological Methods \& Research, 19(4), 493-510. https://doi.org/10.1177/0049124191019004003

Jaeger, D. A., Dohmen, T., Falk, A., Huffman, D., Sunde, U., \& Bonin, H. (2010). Direct evidence on risk attitudes and migration. Review of Economics and Statistics, 92(3), 684-689. https://doi.org/10. 1162/Rest_a_00020

Kim, J. H., Pagliara, F., \& Preston, J. (2005). The intention to move and residential location choice behaviour. Urban Studies, 42(9), 1621-1636.

Kley, S. (2017). Facilitators and constraints at each stage of the migration decision process. Population Studies, 71(sup1), 35-49. https://doi.org/10.1080/00324728.2017.1359328

Koikkalainen, S., \& Kyle, D. (2016). Imagining mobility: The prospective cognition question in migration research. Journal of Ethnic and Migration Studies, 42(5), 759-776. https://doi.org/10.1080/ 1369183X.2015.1111133

Kuhfeld, W. F., Tobias, R. D., \& Garratt, M. (1994). Efficient experimental-design with marketingresearch applications. Journal of Marketing Research, 31(4), 545-557. https://doi.org/10.2307/ 3151882 
Kureková, L. (2013). Welfare systems as emigration factor: Evidence from the new accession States. JCMS: Journal of Common Market Studies, 51(4), 721-739. https://doi.org/10.1111/jcms.12020

Lafleur, J. M., \& Mescoli, E. (2018). Creating undocumented EU migrants through welfare: A conceptualization of undeserving and precarious citizenship. Sociology-the Journal of the British Sociological Association, 52(3), 480-496. https://doi.org/10.1177/0038038518764615

Louviere, J. J., Hensher, D. A., \& Swait, J. D. (2000). Stated choice methods: Analysis and applications. Cambridge University Press.

Massey, D. S. (1998). Worlds in motion: Understanding international migration at the end of the millenium. Oxford University Press.

Montgomery, J. M., Nyhan, B., \& Torres, M. (2018). How conditioning on posttreatment variables can ruin your experiment and what to do about it. American Journal of Political Science, 62(3), 760-775.

Petzold, K. (2017). Mobility experience and mobility decision-making: An experiment on permanent migration and residential multilocality. Population, Space and Place. https://doi.org/10.1002/psp. 2065

Razin, A., \& Wahba, J. (2015). Welfare magnet hypothesis, fiscal burden, and immigration skill selectivity. Scandinavian Journal of Economics, 117(2), 369-402. https://doi.org/10.1111/sjoe.12092

Remhof, S., Gunkel, M., \& Schlaegel, C. (2014). Goodbye Germany! The influence of personality and cognitive factors on the intention to work abroad. International Journal of Human Resource Management, 25(16), 2319-2343. https://doi.org/10.1080/09585192.2014.884613

Ruhs, M. (2015). Is unrestricted immigration compatible with inclusive welfare states? The (un)sustainability of EU exceptionalism. University of Oxford.

Sauer, C., Auspurg, K., Hinz, T., \& Liebig, S. (2011). The application of factorial surveys in general population samples: The effects of respondent age and education on response times and response consistency. Survey Research Methods, 5(3), 89-102.

Schewel, K. (2019). Understanding immobility: Moving beyond the mobility bias in migration studies. International Migration Review. https://doi.org/10.1177/0197918319831952

Snijders, T. A. B., \& Bosker, R. J. (2012). Multilevel analysis: An introduction to basic and advanced multilevel modeling (2nd ed.). Sage.

Stark, O. (1990). On the economics of international labour migration. Population Studies, 44(1), 181-182.

Stark, O., \& Taylor, J.E. (1991). Migration incentives, migration types - the role of relative deprivation. Economic Journal, 101(408), 1163-1178.

Tharenou, P. (2008). Disruptive decisions to leave home: Gender and family differences in expatriation choices. Organizational Behavior and Human Decision Processes, 105(2), 183-200. https://doi.org/ 10.1016/j.obhdp.2007.08.004

Tillema, T., van Wee, B., \& Ettema, D. (2010). The influence of (toll-related) travel costs in residential location decisions of households: A stated choice approach. Transportation Research Part a: Policy and Practice, 44(10), 785-796.

Van Dalen, H. P., \& Henkens, K. (2008). "Emigration intentions: Mere words or true plans? explaining international migration intentions and behavior". Discussion Paper 2008-60. Tilburg, The Netherlands: Center for Economic Research, Tilburg University.

van Dalen, H. P., \& Henkens, K. (2013). Explaining emigration intentions and behaviour in the Netherlands, 2005-10. Population Studies-A Journal of Demography, 67(2), 225-241. https://doi.org/10. 1080/00324728.2012.725135

Van De Vyvere, Y. (1994). Stated preference decompositional modelling and residential choice. Geoforum, 25(2), 189-202.

Van Mol, C. (2016). Migration aspirations of European youth in times of crisis. Journal of Youth Studies, 19(10), 1303-1320. https://doi.org/10.1080/13676261.2016.1166192

Van Mol, C., Caarls, K., \& Souto-Otero, M. (2018). International student mobility and labour market returns: unpacking the importance of level of study, type of mobility, and international prestige hierarchies. Paper presented at the DZHW workshop 'Heterogeneous effects of studying abroad'.

Walker, B., Marsh, A., Wardman, M., \& Niner, P. (2002). Modelling tenants' choices in the public rented sector: A stated preference approach. Urban Studies, 39(4), 665-688.

Wallander, L. (2009). 25 years of factorial surveys in sociology: A review. Social Science Research, $38(3), 505-520$.

Williams, A. M., Jephcote, C., Janta, H., \& Li, G. (2018). The migration intentions of young adults in europe: a comparative, multilevel analysis. Population Space and Place, 24(1), e2123. 
Publisher's Note Springer Nature remains neutral with regard to jurisdictional claims in published maps and institutional affiliations. 